Committee is intended; but it is to be hoped it will adhere to its original classification. J. MARK BALDWIN. Oxford, December I8.

\section{The Stockholm Fisheries Conference and British Fishery Investigations.}

FROM Mr. H. M. Kyle's letter in your issue of December I4, it is clear that he is ignorant of the present position of the British Government with regard to fishery investigations. The great obstacle in the way of such investigations, as every one who has taken any part whatever in their organisation is aware, has always been the want of adequate funds to carry on the researches. The investigations, if properly conducted, are very expensive, involving not only the employment of highly-trained naturalists, but also the equipment of laboratories on shore and of sea-going ships capable of visiting the fishing grounds. The latter item is so costly, that no vessel capable of keeping the sea has yet been systematically employed for scientific fishery work in British waters.

On account of the expense, there is little likelihood of investigations upon an adequate scale being attempted without the use of public money. This is recognised by the Govern ment, and money has been spent by H.M. Treasury for biological and fishery researches in three different directions. In England the Marine Biological Association of the United Kingdom, which was started by private effort in order to promote (to use Prof. Huxley's words) "researches leading to the improvement of zoological and botanical science, and to an increase of our knowledge as regards the food, life-conditions and habits of British food-fishes and molluscs," received in I885 a Government grant of 5000 l. towards the cost of the erection of the first laboratory at Plymouth, and has since received an annual grant, which from 1892 has been 1000 . Altogether some $13,000 \%$. of Government money has been spent, in addition to an equal amount derived from private sources.

In Scotland the Fishery Board receives from the public funds a yearly sum for scientific investigations which amounts, I believe, to about $3000 \mathrm{l}$. ; whilst in Ireland a single sum of $2,500 l$. has recently been granted to assist the fishery investigations of the Royal Dublin Society.

We may now examine in more detail the position of each of the three bodies entrusted by the Government with the expenditure of money for fishery work in England, Scotland, and Ireland respectively.

At the time of the foundation of the Marine Biological Association, the Government, in making the first grant of money, placed upon the Association the responsibility of doing for England work of the kind done in Scotland by the scientific department of the Fishery Board. Encouraged by the support received from public and private sources, the Association proceeded to lay down the necessary machinery for carrying out both scientific and economic work, and a sum of $12,000 l$. was spent in building and equipping the Laboratory at Plymouth as a first step in that direction.

The foundations of the Association were laid upon a liberal scale, involving the expenditure of a considerable capital, but the superstructure remained to be built. The subsequent yearly financial support was not on a scale commensurate with that given to the Association on its foundation, and it has never been possible to make full use of the machinery provided. By far the greater portion of the income of the Association is necessarily devoted to expenses of establishment and organisation, and only a small sum remains for the employment of naturalists to conduct investigations. The funds have never reached a figure which would render the maintenance of a sea-going vessel with which to reach the fishing grounds a question which could be practically considered. Having regard to the money at its disposal, the Association may fairly claim to have produced a body of work which in quality will compare with that done by any similar organisation elsewhere. It must not be supposed, however, that one man can produce the work of six, and it has never been possible to employ at Plymouth more than one naturalist devoting his attention to fishery work.

When, five years ago, the Council did me the honour of appointing me to the executive office of the Association, I undertook the duties of the post knowing that the justification for the yearly expenditure in maintaining the Laboratory in a state of efficiency lay, not in the amount of work which could be im- mediately produced, but in the fact that a solid foundation had been laid, which was capable, with an increased income, of producing a very large amount of valuable work. Further experience has confirmed this view, and I have also been forced to admit, perhaps reluctantly, that the only practical method by which the necessary increase of income can be obtained is by the development, on the part of the Government, of the fishery branch of the work. That the work of the Association was never intended to be confined to what can be done at Plymouth is shown not only by its name and the avowed objects of its promoters, but also by the fact that for a number of years the Association maintained a naturalist and kept open a laboratory at Grimsby for the study of North Sea fisheries. The investigations made by Mr. Holt and Mr. Cunningham in this connection will, in usefulness, rank with the best fishery work which has been done in the North Sea, and it was due only to lack of funds that these investigations could not be continued.

Turning now to the Scottish Fishery Board, it will be admitted that, so far as its scientific investigations are concerned, a similar condition of things exists, in a less pronounced degree. For years an urgent appeal for a steamer capable of keeping the sea has been a constantly recurring feature in the Reports of the Board, and the scientific superintendent will be the first to agree with me in saying that the scientific staff is by no means numerically strong enough to carry out the investigations upon the scale which their importance and difficulty demand.

In Ireland, where the Royal Dublin Society is working in close connection with the fishery inspectors, and is supported by Government money, it has also been impossible to provide a proper vessel, and Mr. Holt is working single-handed, except for occasional volunteer help, although he has accommodation for a number of naturalists.

All past experience has shown that the British Government is very reluctant to spend money upon scientific investigations of any kind, and at the present time it is practically certain that any increased expenditure in this direction will be limited in amount. It is of the utmost importance that what money is spent should be put to the best possible use. Under the circumstances described, and considering the amount of public money which has already been expended on organisations and establishments, all of which are awaiting development to produce their full return of work, I cannot see any justification for asking the Government, as a next step, to provide a considerable sum for a new organisation with a new laboratory, which to judge by all that has happened in the past would soon find itself as unable as its predecessors to adequately carry out its schemes, from the want of proper financial support.

The first demand should be for such a slight reorganisation of existing bodies as will bring them into working contact, a rearrangement which could be brought about with little if any increase of expenditure, and a proper provision of ships and naturalists for carrying out the investigations. When this has been obtained the co-ordination of British investigations with those of neighbouring countries will be a matter of no great difficulty, and one which, in my opinion, can be carried out with no such expenditure for organisation as that suggested by the Stockholm Conference.

As Mr. Kyle has seen fit to introduce matters of a somewhat personal nature into his letter, I may, perhaps, be permitted to say that I make no pretence whatever of being a specialist in fishery investigation, my scientific work having for the most part lain in other directions, nor is it my intention to attempt to alter this condition of things. Should the Government see fit to largely develop the work of the Marine Biological Association on the lines I have indicated, I fully realise that they will wish to have in the executive post a specialist in fishery matters, and this is an eventuality which I am prepared to meet. I should also add that the opinions expressed in this letter are entirely of a personal nature, and I am quite unaware whether or not they would be shared by a majority of the members of the Council of the Association.

The Laboratory, Plymouth, December 16, 1899.

\section{Dr. W. Kobelt and the Mediterranean Fauna.}

THE second part of Dr. W. Kobelt's "Sturien zur Zoogeographie" has been in my hands since its issue, viz., about a year ago, and I have had ample time to become fully acquainted with its

NO. I 575 , VOL. 6I] 